\title{
O paradoxo do espectador em Rancière
}

\author{
Jean Raphael Zimmermann Houllou* \\ Dilma Beatriz Rocha Juliano**
}

Resenha de: RANCIÈRE, Jacques. O espectador emancipado. São Paulo: WMF; Martins Fontes, 2012.

Importante pensador francês, Jacques Rancière participa da cena crítica mundial desde 1995 com a publicação de La mésentente. Politique et philosophie; traduzido e publicado no Brasil em 1996 - O desentendimento. Política e filosofia. A ênfase de sua crítica e a importância de ser lido recaem sobre a análise que ele faz sobre a política da arte e da cultura contemporâneas. Os três regimes estéticos - o ético, o representativo e o estético - que percorrem sua obra constituem a filosofia política da qual se ocupa.

O livro $O$ espectador emancipado ${ }^{1}$ de Jacques Rancière, do qual se ocupa esta resenha, traz uma reunião de textos de conferências realizadas pelo autor em diversas instituições. Ele teve origem a partir do pedido feito ao autor para considerar a reflexão de um grupo de artistas acerca de outra obra sua, $O$ mestre ignorante. Rancière aponta que inicialmente a proposta lhe causou certa perplexidade, pois $O$ mestre ignorante foi escrito com o intuito de se inserir no debate sobre a escola pública e o grupo de artistas havia refletido sobre a condição do espectador. No entanto, num segundo momento, Rancière considerou que estabelecer uma relação entre sua obra anterior e a questão do espectador poderia ser uma oportunidade para um distanciamento radical dos pressupostos teóricos que sustentam os debates sobre as formas de espetáculo teatral, as quais colocam corpos em ação diante de um público. A lógica da emancipação intelectual aplicada à relação entre mestre e aprendiz se estabelece, então, como o fio que percorre a crítica sobre a "posição" paradoxal atribuída ao espectador, ao longo da história da arte.

\section{O espectador emancipado}

\footnotetext{
* Mestre em Patrimônio Cultural e Sociedade/UNIVILLE. Estudante de doutorado do Programa de Pós-graduação em Ciências da Linguagem/UNISUL, na linha de pesquisa Linguagem e Cultura. Professor no Instituto Federal de Santa Catarina

** Mestre em Literatura Brasileira e Doutora em Teoria Literária/UFSC. Professora do Programa de Pós-graduação em Ciências da Linguagem/UNISUL, na linha de pesquisa Linguagem e Cultura, e na Graduação em Cinema e Audiovisual/UNISUL

${ }^{1}$ Referência completa do livro resenhado: RANCIÈRE, Jacques. O espectador emancipado. São Paulo: WMF Martins Fontes, 2012
} 
No primeiro texto, cujo título dá nome ao livro, a autor afirma que "os pressupostos teóricos que põem a questão do espectador no cerne da discussão sobre as relações entre arte e política" (Rancière, 2012, p. 8) podem ser reunidos numa "fórmula essencial" que nomeia por paradoxo do espectador. Tal modelo parte de duas premissas que colocam a condição de espectador como um mal. A primeira afirma que o espectador é o contrário do conhecer, entende que o mesmo desconhece a realidade do processo de produção da aparência que é colocada diante dele no espetáculo. Já a segunda, apresenta o espectador como o contrário do agir, pois cabe a ele permanecer imóvel diante do que Ihe é apresentado. O paradoxo instala-se uma vez que "não teatro sem espectador". (Idem, p.8)

Para Rancière, a dedução mais lógica que decorre do paradoxo sobre o espectador é a de que o teatro seria uma cena de ilusão e passividade. Platão, colocado na origem dessa visão, considerava a mímese teatral como o lugar em que ignorantes vão assistir sofredores. Para o filósofo grego, a comunidade coreográfica, Khorea, na qual todos participavam ativamente era o oposto ao teatro.

No entanto, uma conclusão diferente da platônica prevaleceu entre os críticos do teatro. Partindo do mesmo paradoxo, entenderam que o teatro precisava superar a relação passiva com o público. Nas palavras de Rancière, os críticos compreendiam que: "É preciso um teatro sem espectadores, em que os assistentes aprendam em vez de ser seduzidos por imagens, no qual eles se tornem participantes ativos em vez de serem voyeurs passivos." (Idem, p.9)

Os trabalhos de Brecht e de Artaud, para Rancière, são tentativas de realizar tal inversão. O teatro épico de Brecht entendia que os espectadores não deveriam se identificar com os personagens da cena. Ao contrário, o espetáculo deveria mostrar algo estranho, inabitual, um enigma cujo sentido os espectadores tivessem que buscar como cientistas quando observam os fenômenos e procuram suas causas. Dessa forma, o público se tornaria consciente de sua situação social ao mesmo tempo em que desejaria transformá-la. Já o teatro da crueldade de Artaud propunha um dilema ao espectador semelhante aos das pessoas nas decisões da ação. Dessa forma, o espectador deveria ser arrastado para a ação cênica na posição do ser na posse de suas energias vitais integrais. Assim, Ranciére compara as duas formas teatrais entendendo que enquanto para Brecht o espectador deveria ganhar distância e refinar a observação, para Artaud deveria se aproximar ao máximo perdendo sua condição de observador. Nas palavras de Ranciére: "Os reformadores do teatro reformularam a oposição platônica entre Khorea e teatro como oposição entre verdade do teatro e o simulacro do espetáculo." (Idem, p.11) Para os reformadores, estava na verdade do teatro a possibilidade de constituição estética, outrora considerada na comunidade coreográfica, pela qual o público iria confrontar-se com ele mesmo e colocar-se de forma ativa. Em ambas, ao público era apresentada uma verdade, um sentido de teatro.

Rancière propõe que sejam revistos os pressupostos que sustentam a oposição entre verdade do teatro e o simulacro do espetáculo. Ele afirma que esses pressupostos se configuram num jogo de equivalências e oposições. As equivalências se dão entre público teatral e comunidade, olhar e passividade, exterioridade e 
separação, mediação e simulacro. As oposições, por sua vez, são entre coletivo e individual, imagem e realidade viva, atividade e passividade, posse de si e alienação.

Para o autor, as ideias contidas na obra $O$ mestre ignorante ajudam a reformular as questões acima. Tal livro descreve a relação pedagógica do embrutecimento, a qual considera que existe uma distância interminável entre a posição do mestre e o do ignorante. Sob tal ótica, o primeiro apenas pode aproximar o seu saber da ignorância do segundo se recriar incessantemente tal distância, pois sua posição exige que esteja sempre um passo a frente. Já a emancipação intelectual, também descrita na obra, prega a igualdade das inteligências. Segundo ela, o ignorante não precisa transpor um abismo entre a sua ignorância e o saber do mestre, mas apenas cruzar o caminho daquilo que já sabe até aquilo que ignora, apreendendo signo após signo a relação entre o que ignora e o que sabe. O mestre ignorante é aquele que ignora a noção de inteligências desiguais, para ele não existem fronteiras e hierarquias fixas nas posições do mestre e do ignorante.

Jacques Rancière afirma que os pedagogos embrutecedores compartilham conviç̧ões com os reformadores teatrais. A primeira é a de que existe um abismo separando as posições dos espectadores, passiva, e dos artistas, ativa. Oposição entre o olhar e o saber que define uma "partilha do sensível" pela qual existe uma distribuição apriorística de posições e capacidades vinculadas a elas. Rancière pergunta se o que cria a suposta distância entre o espectador e o artista não é exatamente o desejo de eliminá-la. Afirma que considerando a emancipação intelectual, podemos ponderar que olhar também é agir.

Dessa forma, o espectador, assim como o aluno, também age selecionando, comparando e interpretando. Além disso, ele critica a noção de que ação do espectador é pré-determinada pelo artista, como prega a lógica do pedagogo embrutecedor segundo a qual o aluno deve apreender aquilo que o mestre faz apreender. Ao contrário, escreve que "os espectadores vêem, sentem e compreendem alguma coisa à medida que compõe seu próprio poema, como o fazem, à sua maneira, atores ou dramaturgos, diretores, dançarinos ou performers." (Idem, p.18) Decorre disso que a noção do teatro como algo essencialmente comunitário, diferente da televisão e do cinema, a exemplo da comunidade coreográfica platônica, também pode ser questionada.

$\mathrm{Na}$ lógica da emancipação sempre a uma terceira coisa, como, por exemplo, um livro que é estranho ao mestre e ao aluno. Da mesma forma, no teatro, a performance não é a transmissão do saber do artista ao espectador numa relação de causa e efeito controlada pelo primeiro. Ela é a terceira coisa entranha ao artista e ao espectador cujo domínio nenhum deles possui.

\section{Desventuras do pensamento crítico}

No segundo texto, Rancière afirma que a tradição da crítica social e cultural é bastante questionada atualmente por pessoas que afirmam sua obsolescência em razão de não haver mais uma sólida realidade para se opor ao reino das aparências. Contudo, na visão do autor, apesar desse descrédito para com a crítica social e 
cultural, os seus pressupostos continuam funcionando muito bem, inclusive no discurso dos que afirmam sua superação. Ocorre que seu uso atual manteve as mesmas bases apenas invertendo o sentido. Para exemplificar tal manifestação, Rancière propõe examiná-la em três domínios: da arte, da teoria e da política.

No domínio da arte, o autor busca analisar obras de grandes exposições internacionais que se propõe a refletir sobre o estado do mundo. Para tanto, descreve duas obras que se valem do efeito da colagem para promover um choque numa mesma superfície de elementos heterogêneos. Uma das obras foi realizada pela artista americana Martha Rosler na década de 70 e apresenta a fotomontagem da imagem de um vietnamita segurando uma criança morta, na Guerra do Vietnã, sobre o fundo de uma casa de campo norte americana. A outra, de autoria de Josephine Meckseper, foi exposta em 2006 e traz uma foto que apresenta em primeiro plano uma lata de lixo transbordando e em segundo plano uma manifestação antiguerra promovida nos Estados Unidos da América. A arte de Rosler acentua que "o choque deveria revelar a violência imperialista por trás da exposição feliz dos bens e das imagens" (Idem, p.32). A fotografia de Meckseper, por sua vez, ressalta a homogeneidade entre os elementos sugerindo que na atualidade tudo possa ter virado um jogo de consumo, terminando com a separação entre a realidade e a aparência e assumindo o risco do próprio dispositivo crítico ter virado uma mercadoria. Apesar dessas diferenças, para o crítico, as duas obras se utilizam do mesmo pressuposto da tradição crítica que pretende mostrar ao espectador o que ele supostamente não quer ver.

Na seqüência, Rancière analisa como o pensamento teórico repete o pressuposto da teoria crítica. Ele inicia citando o filósofo Peter Sloterdijk o qual acredita que a vida atual perdeu muito de sua carga de sofrimento e miséria. No entanto, para Sloterdijk, o sentimento de culpa em relação à miséria sobrevive à perda de seu objeto, por isso a mentira da miséria continuaria sendo expressa no espaço público. Rancière entende que tal idéia retoma novamente a concepção segundo a qual as pessoas são vítimas de uma estrutura global de ilusão diante um processo irresistível de desenvolvimento das forças produtivas. Em suas palavras: "Continuam denunciando a incapacidade de conhecer e o desejo de ignorar. E cravam sempre a culpa no coração da negação." (idem, p.34)

Por fim, o autor analisa a dimensão política. Para ele, atualmente ocorre uma redistribuição das posições políticas. Por um lado, a denúncia contra o império da mercadoria se tornou uma aquiescência irônica e melancólica a esse império. Segundo essa visão, todos os desejos de subversão obedecem também às leis do mercado. Por outro, as energias militantes se voltaram para a direita, segundo as quais os malefícios da mercadoria e do consumo são responsabilidades dos indivíduos democráticos. Essa concepção, trazida a tona após a queda da União Soviética, associa os direitos humanos aos direitos do indivíduo egoísta burguês. Dessa forma, a igualdade a que os indivíduos democráticos pleiteiam é a igualdade entre o vendedor e o comprador de uma mercadoria, ou seja, desejam o triunfo do mercado nas relações humanas. Segundo Rancière, ambas as visões invertem o modelo crítico que pretendiam revelar a lei da mercadoria como a verdade última atrás das aparências para armar os combatentes da luta social. O autor afirma que a lógica da revelação continua em 
curso, no entanto, a mesma não espera mais fornecer alguma arma contra o império capitalista. Dessa forma, a crítica do mercado e do espetáculo fica desarticulada de qualquer forma de emancipação.

Rancière conclui esse capítulo afirmando que é necessário sair da lógica segundo a qual a multidão popular desconhece e é enganada pelas imagens. Segundo ele, há quarenta anos a ciência crítica zombava dos "imbecis" que tomavam imagens por realidades. No entanto, após os "imbecis" terem sido instruídos na arte de reconhecer a realidade por trás das imagens, a crítica faz rir daqueles que acreditam ainda ver mensagens ocultas por trás das imagens. O autor afirma que não quis acrescentar mais uma volta a esses ciclos. Ao contrário, propõe que os considerados incapazes são capazes e que não há funcionamento oculto do império que os aprisionem. Existem, na verdade, cenas de dissenso e não um regime único de engodo. Para Rancière, considerar essa hipótese é pensar numa outra organização do sensível. Em suas palavras: "O dissenso põe em jogo, ao mesmo tempo, a evidência do que é percebido, pensável e factível e a divisão daqueles que são capazes de perceber, pensar e modificar as coordenadas do mundo comum." (Idem, p.49)

\section{Paradoxos da arte política}

Nesse capítulo Rancière escreve que, após o ceticismo dominante quando aos poderes subversivos da arte, surgiram recentemente variadas tentativas de repolitizar a arte. Para ele, todas as formas artísticas com esse intuito compartilham a seguinte visão: "a arte é considerada política porque mostra os estigmas da dominação, porque ridiculariza os ícones reinantes ou porque sai de seus lugares próprios para transformar-se em prática social etc." (Idem, p.52)

Além disso, essas formas supõem ser previsível a relação de causa e efeito entre o trabalho do artista e a reação do público, como se as formas sensíveis de produção artística tivessem uma relação de continuidade com as formas sensíveis de quem as recebe. A esse modelo, nascido na Europa do século XVIII, o autor chama de modelo pedagógico de eficácia da arte.

Atualmente prevalece a noção de uma arte que deve anular a si mesma, como no caso do teatro que tenta transformar o espectador em ator ou da performance que sai do museu para se tornar um gesto na rua. Segundo o autor, essas são formas de opor à pedagogia incerta da mediação representativa, a qual deseja produzir efeitos pela representação, a pedagogia da imediatez ética, cujo objetivo é produzir efeitos pela suspensão dos fins representativos.

Essa polaridade entre as formas artísticas esconde a existência de uma terceira qualidade de eficácia de arte, a eficácia estética. Trata-se de uma eficácia paradoxal que compreende existir uma separação entre as formas sensíveis de produção da arte e os seus efeitos nas formas sensíveis de recepção da mesma. Dessa forma, consubstancia-se numa ruptura estética que permite abolir a visão segundo a qual existem homens de inteligência ativa que dominam outros de passividade material. Torna-se também uma mudança de ordem política à medida que abandona a divisão da sociedade em grupos destinados a obediência e outros ao comando. 
A tradição da arte crítica tentou articular as três eficácias descritas acima. Tentou mobilizar as forças através do efeito ético e aprisionar as possibilidades de multiplicação de sentidos da eficácia estética por meio da continuidade da eficácia representativa. Brecht, por exemplo, tentava produzir no público de suas peças o chamado distaciamento por meio de estórias que criassem estranheza. Acreditava que, a partir disso, seriam gerados dois efeitos: em primeiro lugar, a estranheza iria se dissolver na compreensão de suas razões; na seqüência essa compreensão se transformaria em força de revolta. Brecht desejava fundir o choque estético das sensorialidades diferentes e a correção representativa dos comportamentos, ou seja, a separação estética e a continuidade representativa. Rancière crítica a tentativa de Brecht, pois entende que não há razão para acreditar que seja possível calcular o efeito de um espetáculo sobre os que o recebem.

Essa distância entre a finalidade da arte crítica e sua real eficácia pode ser mantida enquanto algumas formas de interpretação política receberam essas formas de arte e promoveram uma interligação de seus elementos. Contudo, no mundo atual, o qual é considerado como tomado pelo consenso da globalização e, portanto, desprovido dessas formas de interpretação dissensuais, a forma de crítica teve que ser alterada. Agora, ela tende a voltar-se para si mesma numa tendência de autoanulacão. Elas pretendem denunciar o reinado das mercadorias e do consumo, mas como é sabido que os espectadores têm noção de tais questões, o mecanismo gira em torno de si mesmo e se vale da própria indecibilidade de seu dispositivo, pois, não estaria esta própria crítica inserida na lógica do consumo a qual pretende criticar?

Rancière afirma que existem várias maneiras dessa tendência se exprimir. A primeira consiste em diminuir a carga política sobre a arte. A segunda pretende eliminar a distância entre a arte produtora de dispositivos visuais e a transformação das relações sociais, de modo que os dispositivos artísticos se apresentem diretamente como produtores de relações sociais. $O$ autor acredita que a segunda maneira pode ser vista como saída exemplar da arte para fora de si mesma. Segundo Rancière, existe nela uma tendência dessa arte crítica de não criar as relações sociais em geral, mas relações que subvertam os elos sociais bem determinados. Decorre disso, que os artistas aparecem como virtuose e estrategistas, acabando-se por identificar, mais uma vez, a eficácia da arte com a execução das intenções dos artistas. $O$ autor conclui esse capítulo afirmando que não há como evitar a distância estética que separa os efeitos das intenções. Para ele, arte política é aquela que tem conhecimento que seu efeito político passa pela distância estética.

\section{A imagem intolerável}

Neste texto Rancière afirma que o deslocamento do intolerável na imagem para a imagem intolerável esteve no centro das tensões da arte política. Se anteriormente podia-se perceber um choque entre imagens referentes às aparências e imagens que revelavam a realidade por de trás delas; nas práticas contemporâneas considera-se que não existe uma imagem referente à realidade que seja possível opor ao mundo das aparências, todas as imagens estariam num mesmo fluxo de exibição universal. 
Dessa forma, imagens que anteriormente se considerava apresentando uma imagem intolerável passam a ser entendidas como imagens, elas próprias, intoleráveis.

Esse é o caso das pequenas fotografias tiradas de Auschwitz, mostrando um grupo de mulheres sendo empurradas para a câmara de gás, que foram utilizadas na exposição Mémoires des camps apresentada na França. As duas formas de conceber o intolerável aparecem nas críticas à exposição. A de Élisabeth Pagnoux ressaltava a realidade que as fotografias revelavam, dentro da idéia do intolerável na imagem. Já a crítica de Gérard Wajcman afirmava que eram aquelas imagens, por si, intoleráveis já que afastavam o espectador da realidade.

O autor entende que a crítica do espetáculo se associou a visão platônica sobre a passividade dos espectadores e explica que: "Precisamos questionar essas identificações do uso das imagens com a idolatria, a ignorância ou a passividade, se quisermos lançar um olhar novo sobre o que as imagens são, o que fazem e os efeitos que produzem." (Idem, p.94)

No desfecho desse capítulo, o autor aponta para a resistência à antecipação. Segundo sua opinião, o ceticismo contemporâneo com relação à capacidade política das imagens nasceu de uma decepção com o desejo anterior que acreditava ser possível prever a percepção, emoção, compreensão e ação dos espectadores. Por isso, uma nova crença no poder político das imagens deve entender que as imagens não fornecem armas de combates, e que não é possível antecipar seu sentido e efeito; mas contribuem para gerar novas configurações do visível, do dizível e do pensável. Rancière conclui afirmando que as imagens mudam nosso olhar quando seus efeitos e sentidos não pretendem ser antecipados.

\section{A imagem pensativa}

No mais breve dos textos que compõem o livro, mas nem por isso menos denso e assertivo, Rancière assim define a expressão que intitula o texto: "é uma imagem que encerra pensamento não pensado, pensamento não atribuível a intenção de quem a cria e que produz efeito sobre quem a vê sem que este ligue a um objeto determinado" (Idem, p.103). Ela não é algo da natureza de certas imagens. É um jogo de várias funções-imagens numa mesma imagem, um estado intermediário entre a passividade e a atividade e também entre a arte e a não arte. Por essa característica, o autor escolhe a fotografia para abordar a questão da imagem pensativa, uma vez que essa é uma prática também ambivalente nesses pontos.

O retrato de um condenado a morte, Lewis Payne, realizado por Alexander Gardner pouco antes de execução em 1865 é uma das fotografias utilizadas por Rancière para exemplificar o que entende por imagem pensativa. Ele afirma que a singularidade na foto de Gardner se refere a três formas de indeterminação. Em primeiro lugar, não é possível saber se a posição de Lewis Payne entre uma zona de luz e uma de sombra foi uma escolha consciente do fotógrafo ou, se em caso positivo, que motivos o levaram a realizar tal escolha. A segunda indeterminação se refere ao tempo, enquanto a textura da foto marca o passado outros elementos como a roupa, o olhar e a postura do jovem podem ser situados no presente. Por fim, a atitude do 
personagem não revela os seus sentimentos em relação a sua pena ou os motivos que o levaram a cometer o crime. Para o autor, essas indeterminações é que caracterizam a pensatividade da imagem.

A pensatividade também é produto de um estatuto da figura que conjuga dois regimes de expressão sem os homogeneizar.

$\mathrm{Na}$ fotografia, a foto de Walker Evans, pesquisador dos camponeses pobres do Alabama, que apresenta um pedaço de uma parede de uma cozinha com talheres e utensílios sustentados por travessas é um exemplo de imagem pensativa que utiliza dois regimes de expressão. Rancière escreve que tal fotografia não é o registro bruto de um fato social, nem a composição de um alguém que faça arte pela arte. Ela é marcada pela contaminação de duas artes, o excesso literário, do que as palavras projetam sobre aquilo que designam, habita a foto de Evans. Rancière encerra esse capítulo destacando que as novas técnicas e suportes oferecem novas oportunidades de metamorfoses entre os regimes de expressão e, por isso, entende que a imagem continuará sendo pensativa.

O paradoxo, então, tal qual nos apresenta Rancière se constitui e resiste na relação indispensável ao existir da arte - entre o gesto que faz o que olhar que significa, sempre.

Recebido em: 19/10/2013. Aceito em 30/11/2013 